\title{
Protective effects of boron and vitamin E on ethylene glycol-induced renal crystal calcium deposition in rat
}

\author{
${ }^{1}$ Bahadoran H, ${ }^{2}$ Naghit MR, ${ }^{1}$ Mofid M, ${ }^{1}$ Asadi MH, ${ }^{1}$ Ahmadi K, ${ }^{3}$ Sarveazad A \\ ${ }^{1}$ Department of Anatomy, Faculty of Medicine, Baqiyatallah (a.s.) University of Medical Sciences, Tehran, Islamic Repub- \\ lic of Iran; ${ }^{2}$ Department of Nutrition, Health School, Baqiyatallah (a.s.) University of Medical Sciences, Tehran, Islamic \\ Republic of Iran; ${ }^{3}$ Colorectal research center, Iran University of Medical Sciences, Tehran, Islamic Republic of Iran \\ E-mail:naghiimr@yahoo.com
}

Objectives. Kidney stone disease is a common form of renal disease. Antioxidants, such as vita$\min \mathrm{E}$ (Vit $\mathrm{E}$ ) and boron, are substances that reduce the damage caused by oxidation.

Methods. Adult male rats were divided into 5 groups $(\mathrm{n}=6)$. In group 1, rats received standard food and water for 28 days (control group); in group 2, standard rodent food and water with $0.75 \%$ ethylene glycol/d (dissolved in drinking water) (EG Group); in group 3, similar to group 2, with $3 \mathrm{mg}$ of boron/d (dissolved in water) (EG+B Group); in group 4, similar to group 2, with $200 \mathrm{IU}$ of vitamin $\mathrm{E}$ injected intraperitoneally on the first day and the 14th day, (EG+Vit E Group); in group 5, mix of groups 3 and 4, respectively (EG+B+Vit E Group).

Results. Kidney sections showed that crystals in the EG group increased significantly in comparison with the control group. Crystal calcium deposition score in groups of EG+B (160), $\mathrm{EG}+\mathrm{Vit} \mathrm{E}$, and $\mathrm{EG}+\mathrm{B}+\mathrm{Vit} \mathrm{E}$ showed a significant decrease compared to EG group. Measurement of the renal tubules area and renal tubular epithelial histological score showed the highest significant dilation in the EG group. Tubular dilation in the $\mathrm{EG}+\mathrm{B}+\mathrm{Vit} \mathrm{E}$ group decreased compared to the $\mathrm{EG}+\mathrm{B}$ and $\mathrm{EG}+$ Vit $\mathrm{E}$ groups.

Conclusions. Efficient effect of boron and Vit E supplements, separately and in combination, has a complimentary effect in protection against the formation of kidney stones, probably by decreasing oxidative stress.

Key words: boron, vitamin E, kidney stones, oxidative stress, rat

Kidney stone disease is an increasingly common form of renal disease with increasing evidence that reactive oxygen species (ROS) and development of oxidative stress (OS) are produced during idiopathic $\mathrm{CaOx}$ nephrolithiasis. In industrialized countries, about 10 to $12 \%$ of the population is prone to form kidney stones. The prevalence of kidney stones is $12 \%$ in men and $6 \%$ in women. Stones mainly occur between 20-40 years of age and are more likely seen in the overweighed and obese individuals (Scales et al. 2012). Kidney stones are solid pieces formed by a compressed form of substances such as calcium, oxalate, and phosphorus, which are normally found in the urine (NJUDICH 2007). By oxidative stress, apoptosis and necrosis of kidney epithelial cells (Portilla 2014; Thamilselvan et al. 1997), a cascade of events lead to more crystallization, retention, and development of stones (Khan 2004). Ethylene glycol (EG: 1,2-ethanediol, ethane-1,2-diol) is a substance that causes oxidative stress in the kidney and eventually stone formation. It is toxic in its pure form and colorless, odorless, and sweet tasting substance

Corresponding author: Mohammad Reza Naghii, Department of Nutrition, Health School, Baqiyatallah (a.s.) University of Medical Sciences, Tehran, Islamic Republic of Iran; e-mail: naghiimr@yahoo.com. 
(Naghii et al. 2015). Its main industrial use is as an antifreezer for cars and air conditioners. The major toxicity of EG is through the skin and inhalation, but food poisoning inadvertently or deliberately occurs and is considered as a medical emergency. People sometimes drink ethylene glycol mistakenly or on purpose as a substitute for alcohol (Patocka and Hon 2010). EG completely and rapidly gets absorbed through the digestive system and is reabsorbed in the kidneys. Eighty percent of EG is metabolized in the liver and $20 \%$ in the kidney (Hess et al. 2004). Oxalate is a final product of EG metabolism that has very high affinity for binding to calcium in various tissues, including kidney and urine (Poldelski et al. 2001). Thus, in animal studies, EG is used to induce a stone formation.

Antioxidants are substances that reduce the damage caused by oxidation, such as the harm caused by free radicals. They are naturally found in foods and also in the form of dietary supplements such as vitamin $C$, vitamin $A$, vitamin $E$, vitamin B6, selenium, and recently boron is reported to have antioxidant property, too (Naghii et al. 2014a).

Vitamin E (Vit E) is a group of fat-soluble compounds with antioxidant properties in the forms of Tocopherols $(\alpha, \beta, \gamma, \delta)$ and Tocotrienols $(\alpha, \beta, \gamma$, $\delta)$ (IUPAC-IUB JCBN 1982) and $\alpha$-tocopherol are the most abundant and most active biological forms of Vit E (Brigelius-Flohe and Traber 1999). Boron is a trivalent metalloid element having both metallic and non-metallic properties that are not found free in nature, but are present as boric acid, calcium borate, and borax, as the main chemical forms (Kato et al. 2005). Boron is known to play a key role in the inflammatory process, immune function, insulin release, and metabolism of vitamin D (Hunt 1994). It has anti-inflammatory properties with an antioxidant booster. Therefore, it plays an important role against free radicals and oxidative stress state (Naghii 2014; Nielsen 2000; Armstrong and Spears 2003).

Given the role of the oxidative stress in the pathogenesis of kidney perturbation and kidney stone formation, following consumption of EG and the antioxidant properties of Vit $\mathrm{E}$ and boron, the effect of boron and Vit E supplements in the prevention of kidney stone formation in rats was investigated in this study.

\section{Materials and Methods}

Experiments. In this study, 30 adult male Wistar rats weighing 200 to $220 \mathrm{~g}$ were kept in standard conditions with adequate access to food and water with room temperature of $23-25^{\circ} \mathrm{C}$ and $12 \mathrm{~h}$ lightdark cycle. Animals were randomly divided into 5 groups of 6 rats each. In group 1, rats received standard food for rodents and water (control group); in group 2, standard rodent food and water with 0.75 EG/d (dissolved in drinking water) was given for 28 days (EG Group); in group 3, standard rodent food and water with $0.75 \mathrm{EG}$ was given with $3 \mathrm{mg}$ of boron/d (dissolved in water) for 28 days (EG+B Group) ; in group 4, standard rodent food and water with 0.75 EG was given with for 28 days and 200 IU of Vit E was injected intraperitoneally (i.p.) on the first day and the 14th day, respectively (EG+Vit E Group ); in group 5, standard rodent food and water with 0.75 EG with $3 \mathrm{mg}$ of boron/d was given for 28 days and 200 IU of Vit E was injected i.p. on the first day and the 14th day, respectively $(\mathrm{EG}+\mathrm{B}+\mathrm{Vit} \mathrm{E}$ Group).

To provide antioxidant nutrients, 300.0 IU (200 mg) of a softgel capsule of Vit E as dl-Alpha Tocopheryl Acetate (Vitane Pharmaceutical Inc., Costa Mesa, California, USA) was used, and boric acid (Merck, Germany) as the source of boron was added to their drinking water to provide the abovementioned doses/rat, respectively.

All experiments were performed in accordance with the guidelines of the animals care and approved by the University's Research and Ethics Committee.

Microscopic examination of crystal calcium deposition. After 28 days, animals were sacrificed under anesthesia. Excised left kidney tissue samples were fixed with $10 \%$ neutral buffered formalin and serial sections were cut. For the evaluation of crystal calcium deposits, sections were stained with hematoxylin and eosin ( $\mathrm{H} \& \mathrm{E}$, for histopathological investigation) and von-Kossa staining (to detect of crystal calcium deposits).

After von-Kossa staining, photographs were taken from the three regions of the cortex, juxtamedulla, and medulla (9 photos of every region) with the light microscope $\times 400$ magnification. Crystal deposition was quantified into three grades: Small 5.0 = < 15 micron crystals, Medium $15=\leq 30$ micron crystals, Large $=\leq 30$ micron crystals and the average numbers of crystals calcium deposits were counted in each photo by Motic system Image analyzer (Motic Image 20001.2 Micro-Optic Industrial Group Co. Ltd.; Figure 1A).

Assessment of histopathological structure of renal tubules. After $\mathrm{H} \& \mathrm{E}$ staining, photos were taken by an optical microscope with a light microscope $\times 200$ magnification in three regions of the cortex, juxtamedulla, and medulla (9 photos of every region) (Figure 2), and were studied by MOTIC soft- 
ware. Sectional area of the kidney measurement of the area of the renal tubules (measurement of tubular dilation) and tubular epithelial structure were investigated as criteria of histopathological structure. The histological structure scores for all tubules epithelium were recorded. Briefly, the shape and the arrangement of the epithelial cells in an intact tubule were quantified into three grades: 0 - deformation of cuboidal-shaped cells to squamous; 1 - the partial loss of epithelium in some parts of the tubule; 2 - the complete loss of epithelium. Finally, the epithelial structure scores were recorded for each group.

Statistical analysis. Data are expressed as mean \pm SD and a Statistical Package for the Social Sciences ([SPSS 18.0], New York: McGraw-Hill) was used to perform all comparisons, and Two-way ANOVA and Tukey test analysis was used for the comparison of the mean of the score of crystal depositions. A probability of 0.05 was considered statistically significant.

\section{Results}

In Figure 1, crystal calcium depositions are marked in black. Images were prepared in three regions of the cortex, juxtamedulla, and medulla. After the measurement by MOTIC software, of crystal calcium deposition were separately counted in each area according to their sizes (Figure 1).

Determination of crystal calcium deposition number. The number of small, medium and large crystal calcium deposition in the cortex, juxtamedulla, and medulla regions is shown in Table 1.

Crystal calcium deposition in different regions. The number of crystal calcium deposition in the cortex showed that crystals in the EG group increased significantly compared to the control group $(\mathrm{p}<0.001)$. The number of small and medium crystals in groups of $\mathrm{EG}+\mathrm{B}, \mathrm{EG}+\mathrm{V}$ it $\mathrm{E}$ and $\mathrm{EG}+\mathrm{B}+\mathrm{Vit} \mathrm{E}$ significantly reduced compared to EG group $(p<0.001)$. The number of large crystals in $\mathrm{EG}+\mathrm{B}, \mathrm{EG}+\mathrm{Vit} \mathrm{E}$ and $\mathrm{EG}+\mathrm{B}+\mathrm{Vit} \mathrm{E}$ groups had a non-significant reduction compared to EG group. The number of medium size crystals in the group $\mathrm{EG}+\mathrm{B}+\mathrm{Vit} \mathrm{E}$ reduced significantly $(\mathrm{p}<0.001)$ compared to $\mathrm{EG}+\mathrm{B}$ and $\mathrm{EG}+\mathrm{Vit} \mathrm{E}$ groups (Figures 2 and 3 ).

The number of crystals in juxtamedulla showed that all three crystals sizes in the EG group significantly increased compared to the control group $(\mathrm{p}<0.001)$. The number of small and medium-sized crystals in groups of $\mathrm{EG}+\mathrm{B}, \mathrm{EG}+\mathrm{Vit} \mathrm{E}$ and $\mathrm{EG}+\mathrm{B}+\mathrm{Vit} \mathrm{E}$ signifi-

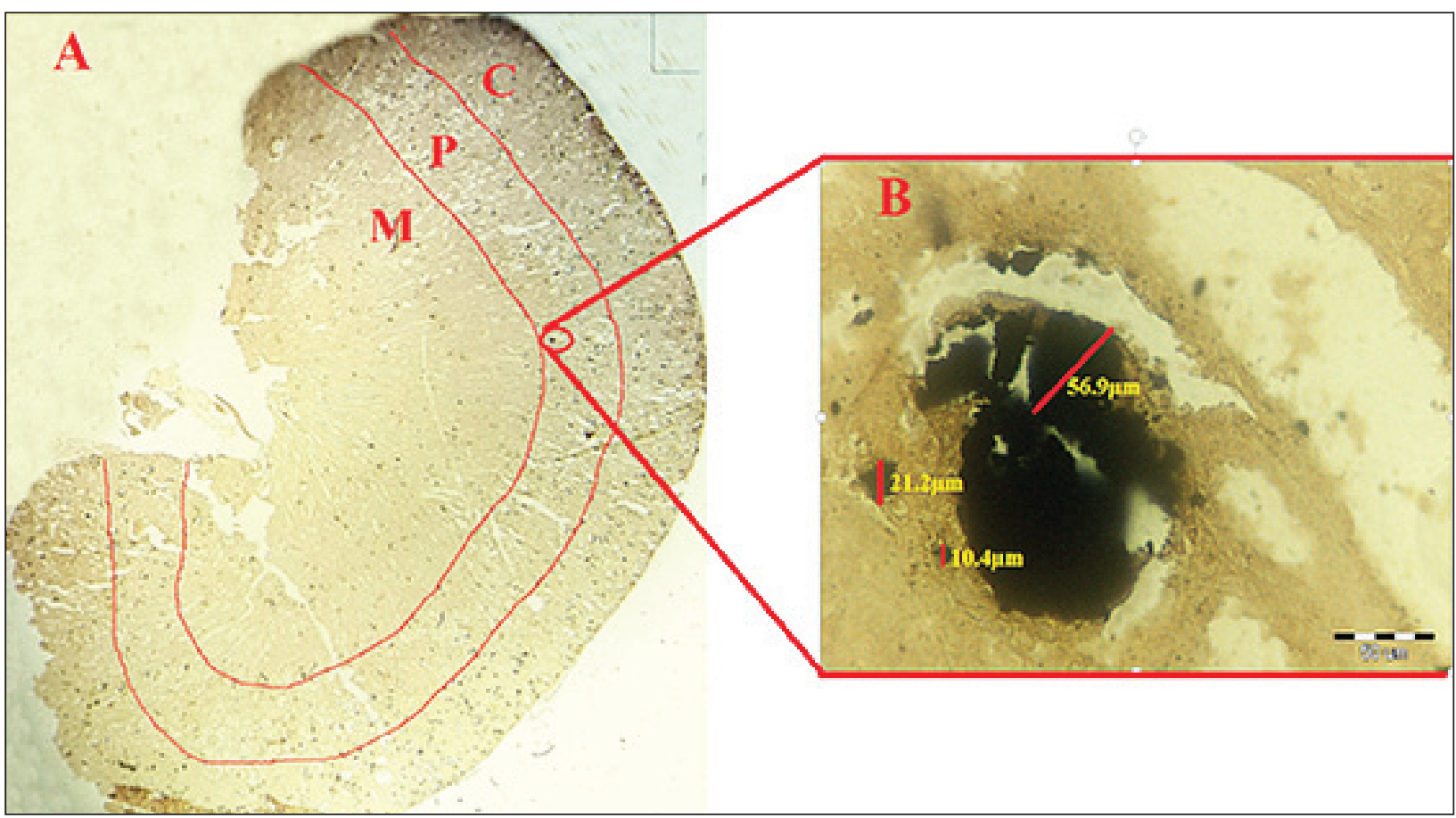

Figure 1. Photomicrograph of kidney section and measurement of crystal calcium deposition. Crystals are depicted in black. A) cortex $(C)$, juxtamedulla (paracortex $=P$ ), and medulla $(M)$ in kidney section. B) images and measurement of crystal deposition size by MOTIC software for stone categorization and scoring system. Crystals observed by light microscope (von Kossa staining, $\times 400$ magnification, bar $=40 \mu \mathrm{m}$ ) in juxtamedulla of EG+B group. 


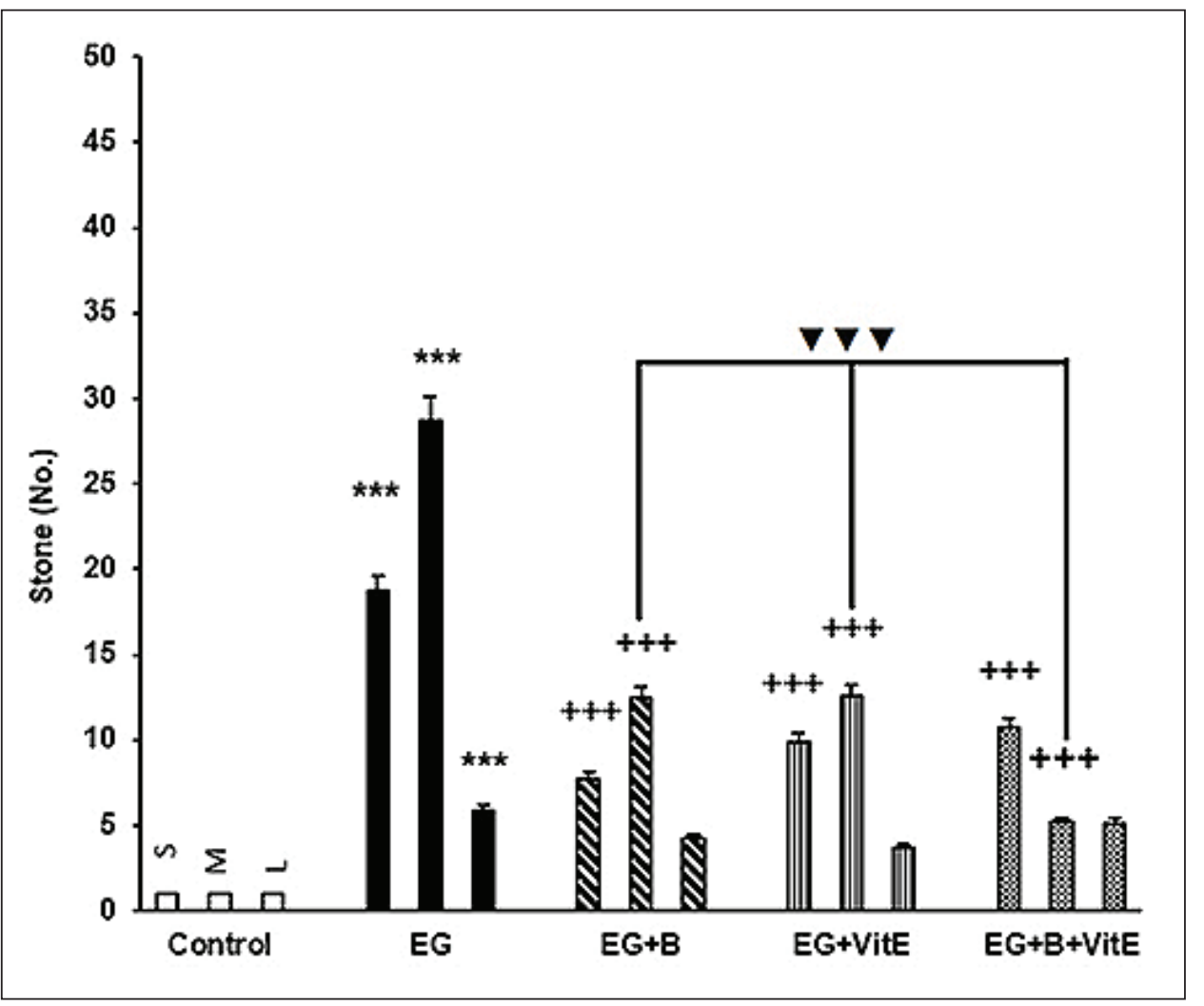

Figure 2. The number of crystal calcium deposition (stones) in the cortex. S - small; M medium; L - large; EG - ethylene glycol; EG+B - ethylene glycol and boron; EG+Vit E - ethylene glycol and vitamin $\mathrm{E}$; EG+B+Vit E - ethylene glycol, boron, and vitamin $E$. ${ }^{* * *} p<0.001$ vs. control group; ${ }^{+++} p<0.001$ vs. EG group; $\sim p \mathrm{p}<0.001$ vs. EG+B and $\mathrm{EG}+\mathrm{Vit} \mathrm{E}$ groups.

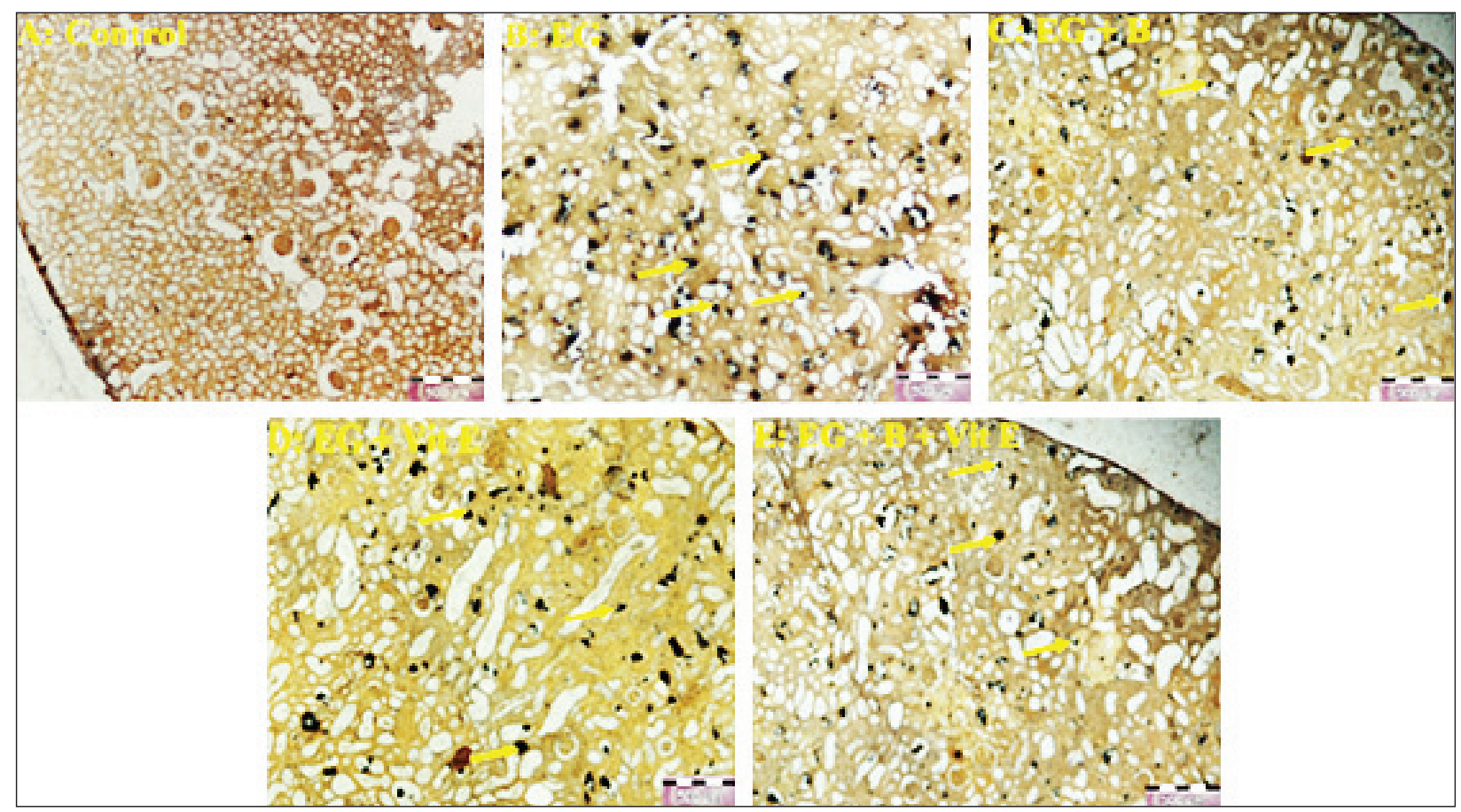

Figure 3. Photomicrograph of crystal calcium deposition formation in cortex. The highest number of crystals was seen in the EG group compared to the supplemented groups. The crystals are shown as scattered black spots (arrow tips). Kidney cortex $x 40$ magnification, von-Kossa staining, bar $=10 \mu \mathrm{m}$. ${ }^{* * *} \mathrm{p}<0.001$ vs. control group; ${ }^{++} \mathrm{p}<0.001 \mathrm{vs}$. EG group; ${ }^{\nabla \nabla} \mathrm{p}<0.001$ vs. EG+B and EG+Vit E groups. 
cantly decreased compared to EG group $(\mathrm{p}<0.001$, $\mathrm{p}<0.01$ for small crystals in EG+Vit $\mathrm{E}$ group). The number of small crystals deposition in the $\mathrm{EG}+\mathrm{B}+\mathrm{Vit}$ $\mathrm{E}$ group decreased significantly compared to the $\mathrm{EG}+\mathrm{B}$ and $\mathrm{EG}+\mathrm{Vit} \mathrm{E}$ groups $(\mathrm{p}<0.05)$. The number of medium crystals in the $\mathrm{EG}+\mathrm{B}+\mathrm{Vit} \mathrm{E}$ group decreased significantly compared to $\mathrm{EG}+\mathrm{B}$ and $\mathrm{EG}+\mathrm{Vit} \mathrm{E}$ groups $(\mathrm{p}<0.001)$.The number of large crystals deposition in the EG+B group was only significantly lower than EG group $(\mathrm{p}<0.05)$ (Figures 4 and 5).

The number of crystals in medulla showed that all three stone sizes in the EG group significantly increased compared to the control group $(\mathrm{p}<0.001)$. The number of small and medium-sized crystals in the $\mathrm{EG}+\mathrm{B}, \mathrm{EG}+\mathrm{Vit} \mathrm{E}$ and $\mathrm{EG}+\mathrm{B}+\mathrm{Vit} \mathrm{E}$ groups significantly decreased compared to EG group $(\mathrm{p}<0.001, \mathrm{p}<0.01$ in $\mathrm{EG}+\mathrm{Vit} \mathrm{E}$ group). The number of large crystals in $\mathrm{EG}+\mathrm{B}, \mathrm{EG}+\mathrm{Vit} \mathrm{E}$ and $\mathrm{EG}+\mathrm{B}+\mathrm{V}$ it $\mathrm{E}$ groups decreased non-significantly compared to EG group. The number of medium crystals deposition in $\mathrm{EG}+\mathrm{B}+\mathrm{Vit} \mathrm{E}$ group decreased significantly compared to $\mathrm{EG}+\mathrm{Vit} \mathrm{E}$ group $(\mathrm{p}<0.05)$ (Figures 6 and 7$)$.
The score of crystal formation based on the crystal calcium deposition (stone) sizes. In Table 2, the estimated score of the stones in cortex, juxtamedulla and medulla are shown separately and all together in the whole kidney in the study groups.

Results showed the highest score for the EG group (272.1) and the lowest score for the $\mathrm{EG}+\mathrm{B}+\mathrm{Vit} \mathrm{E}$ group (121.1). Crystal calcium deposition score in EG showed a significant increase compared to the control group ( $\mathrm{p}<0.001)$. Crystal calcium deposition score in groups of EG+B (160.3), EG+Vit E (132.4), $\mathrm{EG}+\mathrm{B}+\mathrm{Vit} \mathrm{E}$ (121.1) showed a significant decrease compared to EG group ( $<<0.001, \mathrm{p}<0.01$ for $\mathrm{EG}+\mathrm{Vit} \mathrm{E}$ group). Although, crystal calcium deposition score in $\mathrm{EG}+\mathrm{B}+\mathrm{Vit} \mathrm{E}$ group decreased compared to $\mathrm{EG}+\mathrm{B}$ and EG+Vit E groups, but it was not significant (Figure 8).

Renal tubule area measurements in the study groups. Measurement of the area of the renal tubules showed that the average area of tubules in the control group was 1034 square micrometers, 10161 square micrometers in the EG group, 7524 square micrometer in the $\mathrm{EG}+\mathrm{B}$ group, 8489 square micrometers in
Figure 4. The number of crystal calcium deposition (stone) in juxtamedulla. S - small; $M$ - medium; L - large; EG - ethylene glycol; EG+B - ethylene glycol and boron; EG+Vit E - ethylene glycol and vitamin $\mathrm{E} ; \mathrm{EG}+\mathrm{B}+\mathrm{Vit} \mathrm{E}$ - ethylene glycol, boron, and vitamin E. ${ }^{* * *} \mathrm{p}<0.001$ vs. control group; ${ }^{+} \mathrm{p}<0.05$, ${ }^{++} \mathrm{p}<0.01, \quad{ }^{+++} \mathrm{p}<0.001$ vs. EG group; $\nabla \mathrm{p}<0.05$, $\checkmark \nabla \mathrm{p}<0.001$ vs. $\mathrm{EG}+\mathrm{B}$ and $\mathrm{EG}+\mathrm{Vit} \mathrm{E}$ groups.

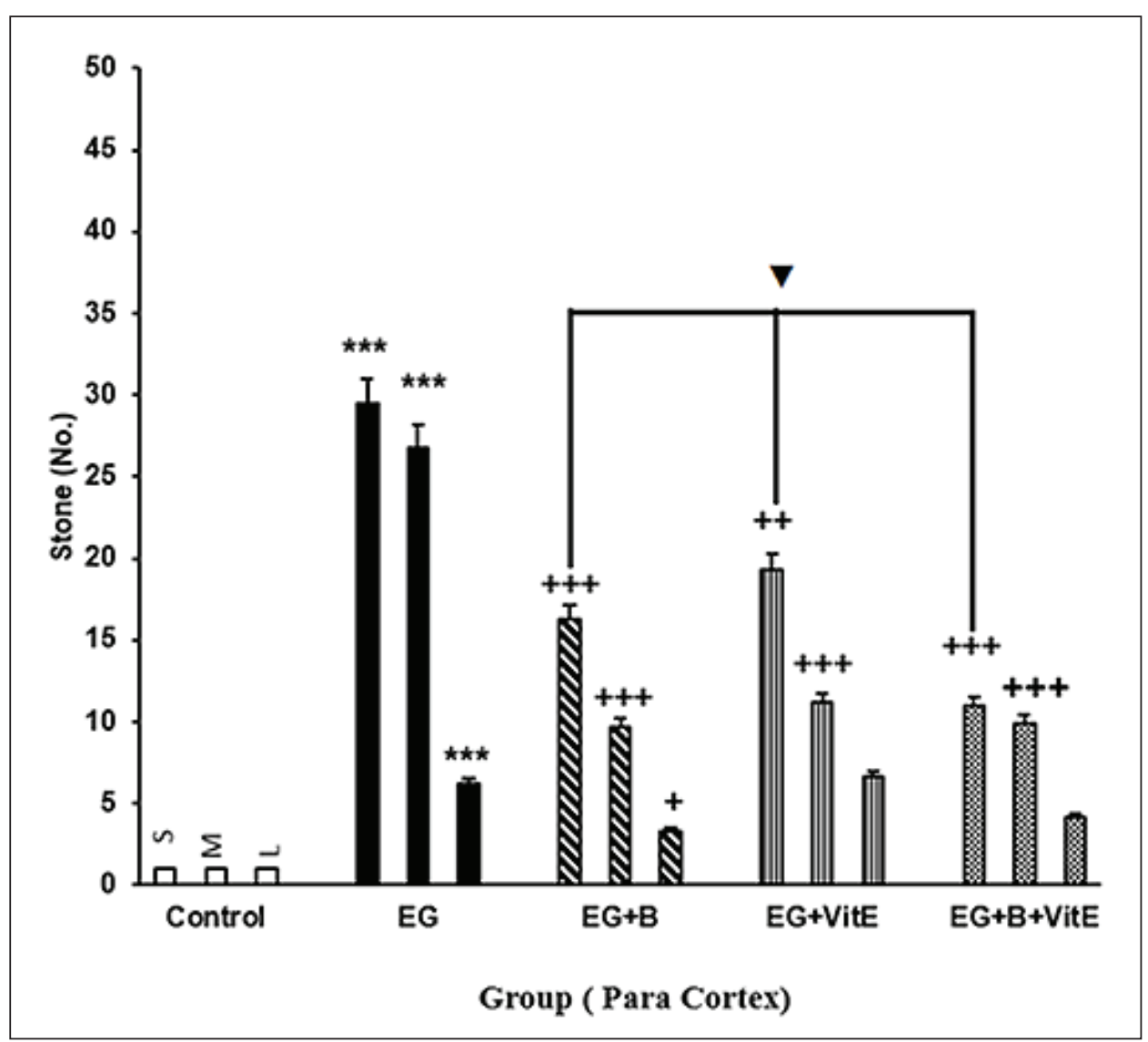




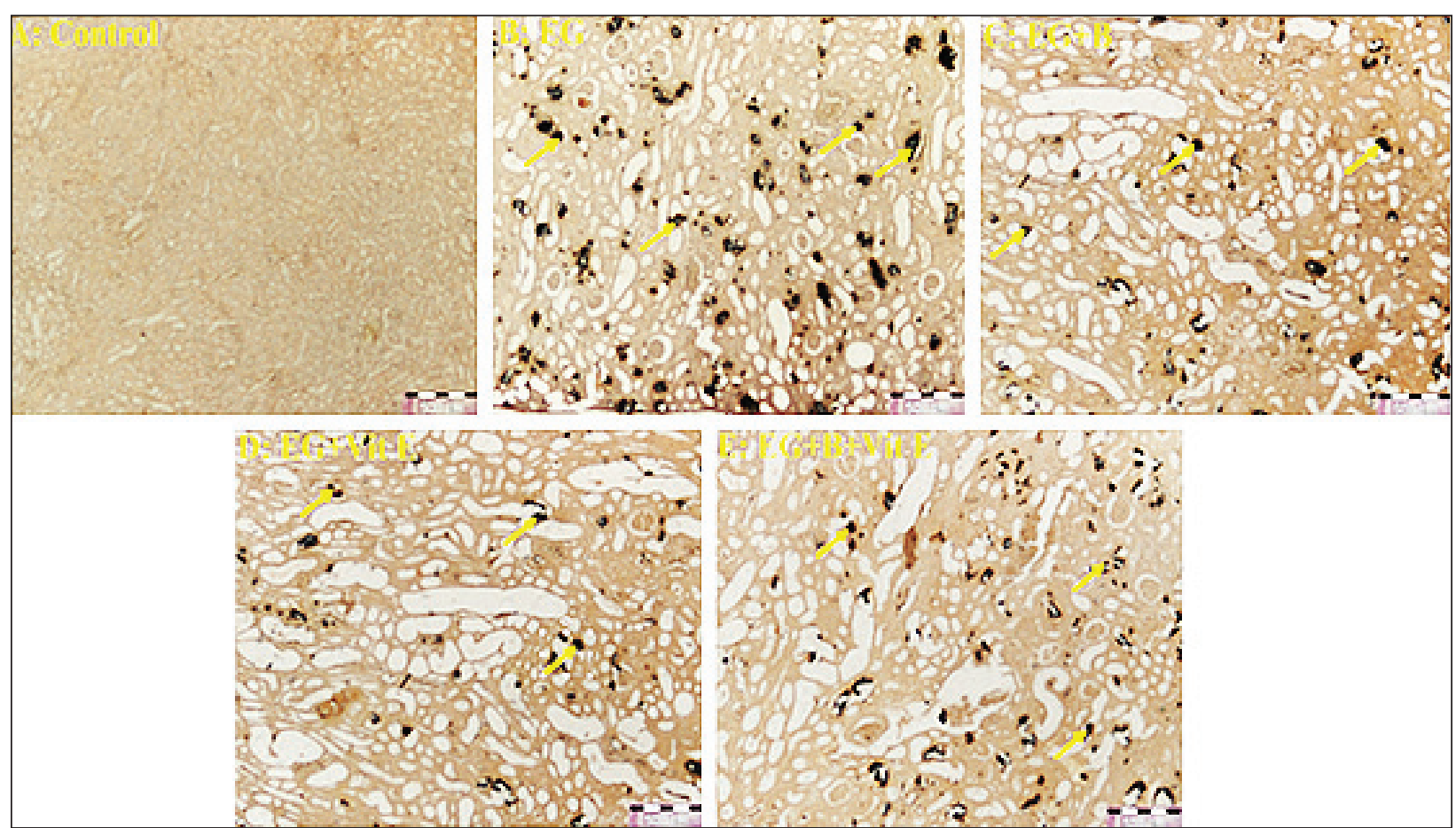

Figure 5. Photomicrograph of crystal calcium deposition formation in juxtamedulla region. The highest number of crystals was seen in the EG group compared to the supplemented groups. The crystals are shown as scattered black spots (arrow tips). Kidney cortex x40 magnification, von-Kossa staining, bar $=10 \mu \mathrm{m} .{ }^{* *} \mathrm{p}<0.001$ vs. control group; ${ }^{+} \mathrm{p}<0.05,{ }^{++} \mathrm{p}<0.01,{ }^{+++} \mathrm{p}<0.001$ vs. EG group; ${ }^{\mathrm{p}} \mathrm{p}<0.05,{ }^{\mathrm{v}}{ }^{\mathrm{v}} \mathrm{p}<0.001$ vs. EG+B and EG+Vit E groups.

the EG+Vit E group, and 5391 square micrometers in the $\mathrm{EG}+\mathrm{B}+\mathrm{Vit} \mathrm{E}$ group, respectively. The average area of the tubules in the EG group increased significantly compared to the control group $(\mathrm{p}<0.001)$. The average area of the tubules in the $\mathrm{EG}+\mathrm{B}, \mathrm{EG}+\mathrm{Vit} \mathrm{E}$ and $\mathrm{EG}+\mathrm{B}+\mathrm{Vit} \mathrm{E}$ groups compared to $\mathrm{EG}$ group had a decline, but it was significant $(p<0.05)$ only in the $\mathrm{EG}+\mathrm{B}+\mathrm{Vit} \mathrm{E}$ group. Tubule areas in the $\mathrm{EG}+\mathrm{B}+\mathrm{Vit} \mathrm{E}$ group compared to the $\mathrm{EG}+\mathrm{B}$ and $\mathrm{EG}+\mathrm{V}$ it $\mathrm{E}$ groups had a non-significant decrease (Figures 9 and 10).

Histopathology score of renal tubular epithelial cells in the study groups. The histopathology score in the control group is zero (as shown nearly zero in the graph), while it was 1.78 in the EG group, 1.48 in the EG+B group, 1.55 in the $\mathrm{EG}+\mathrm{Vit} \mathrm{E}$ group, and 1.22 in the $\mathrm{EG}+\mathrm{B}+\mathrm{Vit} \mathrm{E}$ group. The epithelium histopathology in the EG group increased significantly compared to the control group ( $\mathrm{p}<0.001)$. Although, the epithelium histopathology in the $\mathrm{EG}+\mathrm{B}, \mathrm{EG}+\mathrm{Vit}$ $\mathrm{E}$ and $\mathrm{EG}+\mathrm{B}+\mathrm{Vit} \mathrm{E}$ groups compared to $\mathrm{EG}$ had a decline, but it was only significant in the $\mathrm{EG}+\mathrm{B}+\mathrm{Vit}$ E group $(p<0.05)$. Moreover, the epithelium histopathology in the $\mathrm{EG}+\mathrm{B}+\mathrm{Vit} \mathrm{E}$ group compared to the
$\mathrm{EG}+\mathrm{B}$ and $\mathrm{EG}+\mathrm{Vit} \mathrm{E}$ groups reduced, but this reduction was not significant (Figure 11).

\section{Discussion}

Histopathological findings of our study showed that EG causes tissue damage in the renal tubular epithelium and tubules dilatation. These findings are consistent with the similar findings in other studies.

EG may prevent the mitochondrial respiratory function (Pomara et al. 2008), increase the activity of LDH (Huang et al. 2006), activate caspase 3 , and cause apoptosis in epithelial cells of the kidney and dilation of the renal tubules (Watanabe et al. 2002). It is clear that following EG consumption, many of histopathological kidney damages are due to induction of oxidative stress (Khan 2012; Naghii et al. 2014b). Oxidative stress triggers the destruction of renal tubular epithelial cells through mitochondrial instability, and increased receptor peroxisome proliferator-activated receptor (PPAR) $-\gamma$ triggers the destruction of these cells (Small et al. 2014). Enhancement of renal tubular epithelial cell damage leads to emptying the contents 
Figure 6. The number of crystal calcium deposition (stone) in the medulla. S - small; $M$ medium; L - large; EG - ethylene glycol; EG+B - ethylene glycol and boron; EG+Vit E - ethylene glycol and vitamin E; EG+B+Vit E - ethylene glycol, boron, and vitamin E. ${ }^{* * *} \mathrm{p}<0.001$ vs. control group; ${ }^{++} \mathrm{p}<0.01,{ }^{+++} \mathrm{p}<0.001$ vs. EG group; $\nabla \mathrm{p}<0.05$ vs. EG+Vit E groups.
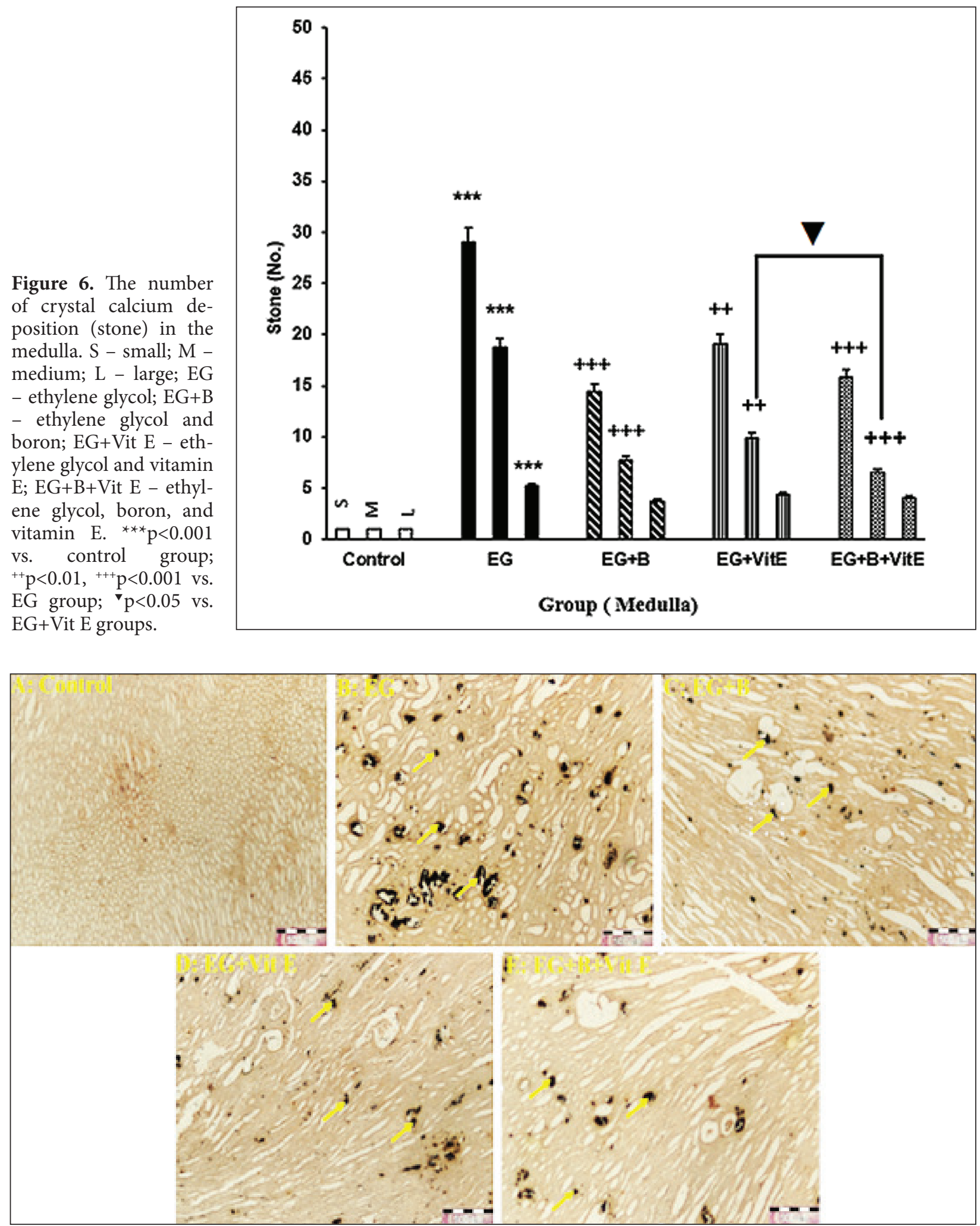

Figure 7. Photomicrograph of crystal calcium deposition formation in medulla region. The highest number of stones was seen in the EG group compared to the supplemented groups. The crystals are shown as scattered black spots(arrow tips). Kidney cortex $\mathrm{x} 40$ magnification, von-Kossa staining, bar $=10 \mu \mathrm{m}$. ${ }^{* *} \mathrm{p}<0.001$ vs. control group; ${ }^{++} \mathrm{p}<0.01$, ${ }^{+++} \mathrm{p}<0.001$ vs. EG group; ’ $\mathrm{p}<0.05$ vs. EG+Vit E groups. 


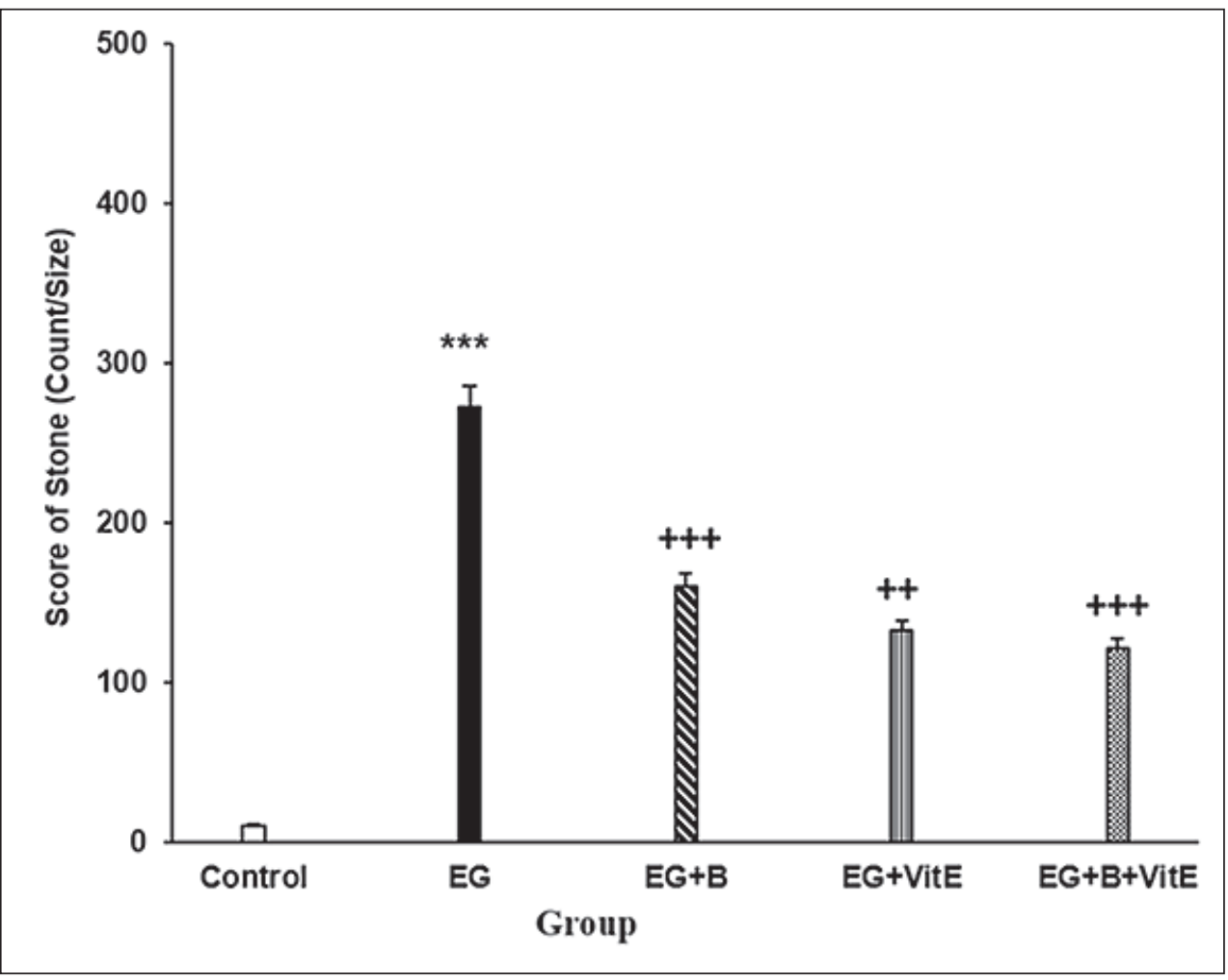

Figure 8. The estimated score of crystal calcium deposition (stone) formation. EG - ethylene glycol; EG+B - ethylene glycol and boron; EG+Vit E - ethylene glycol and vitamin $\mathrm{E}$; $\mathrm{EG}+\mathrm{B}+\mathrm{Vit} \mathrm{E}$ - ethylene glycol, boron, and vitamin $\mathrm{E} .{ }^{* *} \mathrm{p}<0.001$ vs. control group; ${ }^{++} \mathrm{p}<0.01, \quad{ }^{+++} \mathrm{p}<0.001$ vs. EG group.

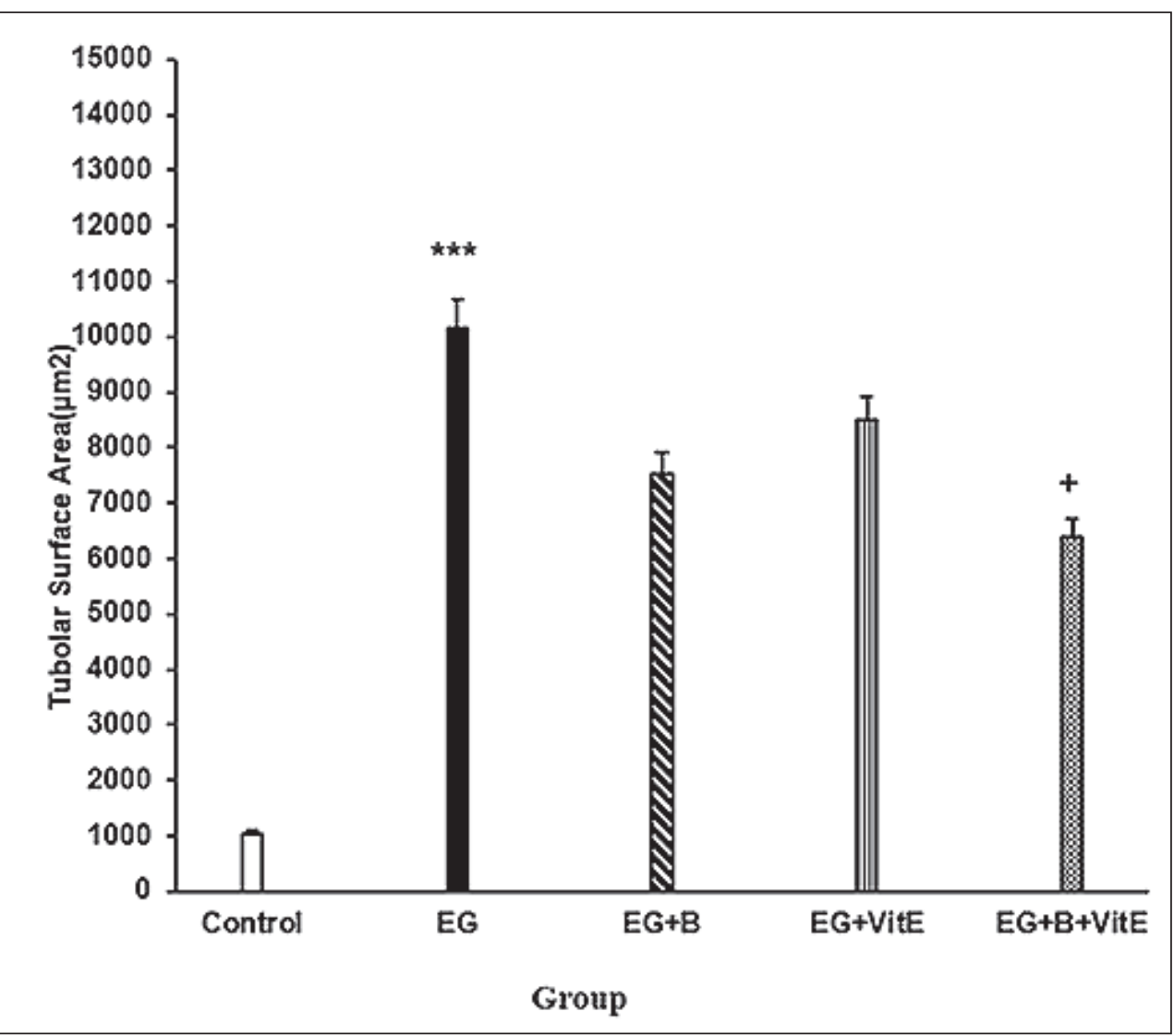

Figure 9. The average area of the renal tubules in the study groups. EG - ethylene glycol; EG+B - ethylene glycol and boron; EG+Vit E - ethylene glycol and vitamin $\mathrm{E}$; $\mathrm{EG}+\mathrm{B}+\mathrm{Vit} \mathrm{E}$ - ethylene glycol, boron, and vitamin $\mathrm{E} .{ }^{* * *} \mathrm{p}<0.001$ vs. control group; ${ }^{++} \mathrm{p}<0.01, \quad{ }^{+++} \mathrm{p}<0.001$ vs. EG group. 


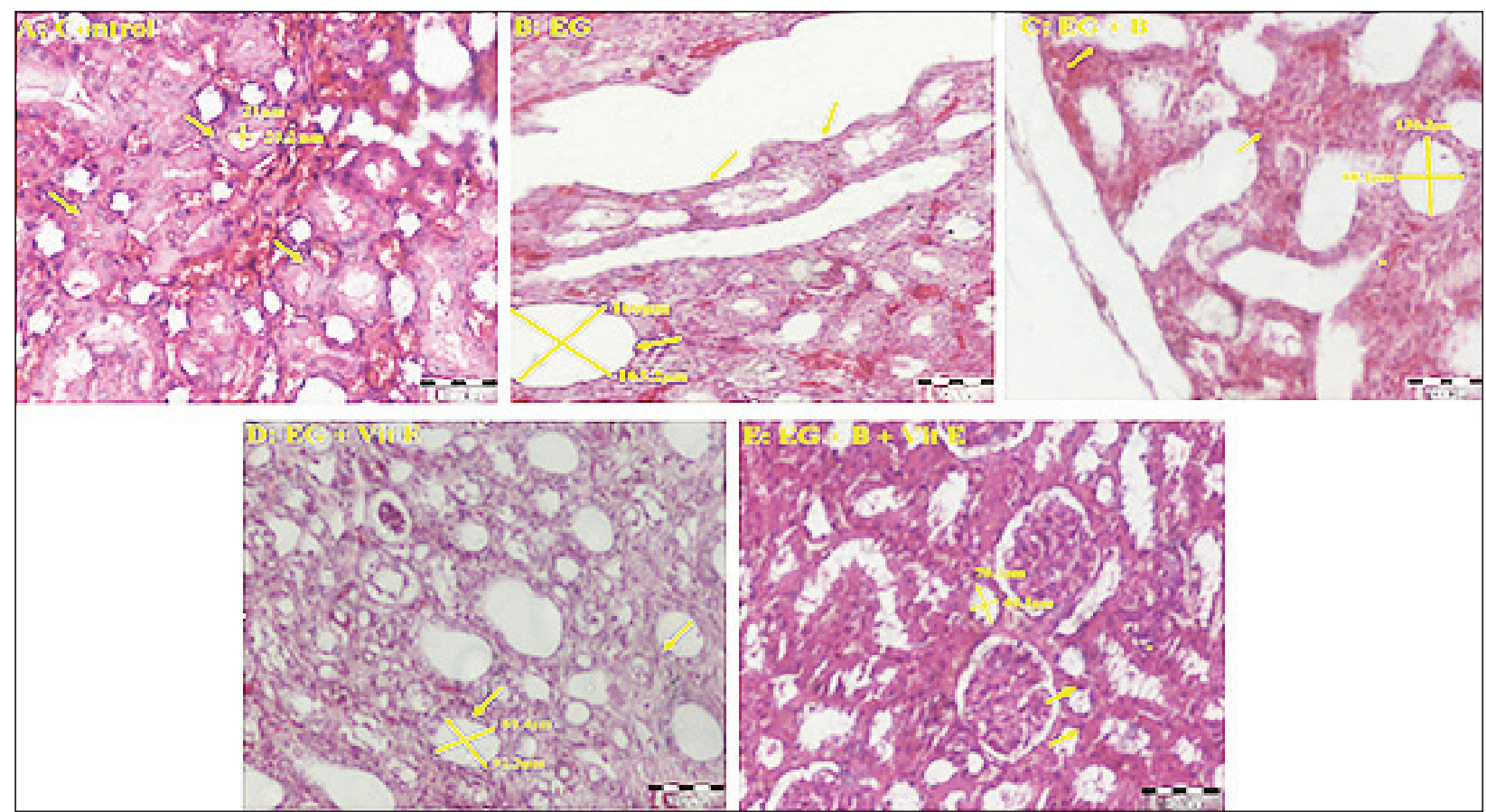

Figure 10. Comparison of the dilatation of the renal tubules in the study groups. The lowest expansion observed in the control group and the highest dilation in the EG group. Tubular dilation in the EG+B, EG+Vit E and EG+B+Vit E groups is lower than the EG group. Tubular dilation in the $\mathrm{EG}+\mathrm{B}+\mathrm{Vit} \mathrm{E}$ group is less compared to the EG+B and $\mathrm{EG}+$ Vit E groups. Arrows are showing the epithelial cells. A-D x200 magnification, bar $=10 \mu \mathrm{m}$. E x400 magnification, bar $=20 \mu \mathrm{m}$. H \& E staining of cortex in all groups. ${ }^{* *} \mathrm{p}<0.001 \mathrm{vs.} \mathrm{control} \mathrm{group;}{ }^{++} \mathrm{p}<0.01,{ }^{+++} \mathrm{p}<0.001 \mathrm{vs}$. EG group.

Figure 11. Renal tubular epithelial histopathological score in the study groups. EG - ethylene glycol; $\mathrm{EG}+\mathrm{B}$ - ethylene glycol and boron; EG+Vit $\mathrm{E}$ - ethylene glycol and vitamin $\mathrm{E}$; $\mathrm{EG}+\mathrm{B}+\mathrm{Vit}$ E - ethylene glycol, boron, and vitamin $\mathrm{E}$. ${ }^{* * *} \mathrm{p}<0.001$ vs. control group; ${ }^{+} \mathrm{p}<0.05$ vs. EG group.

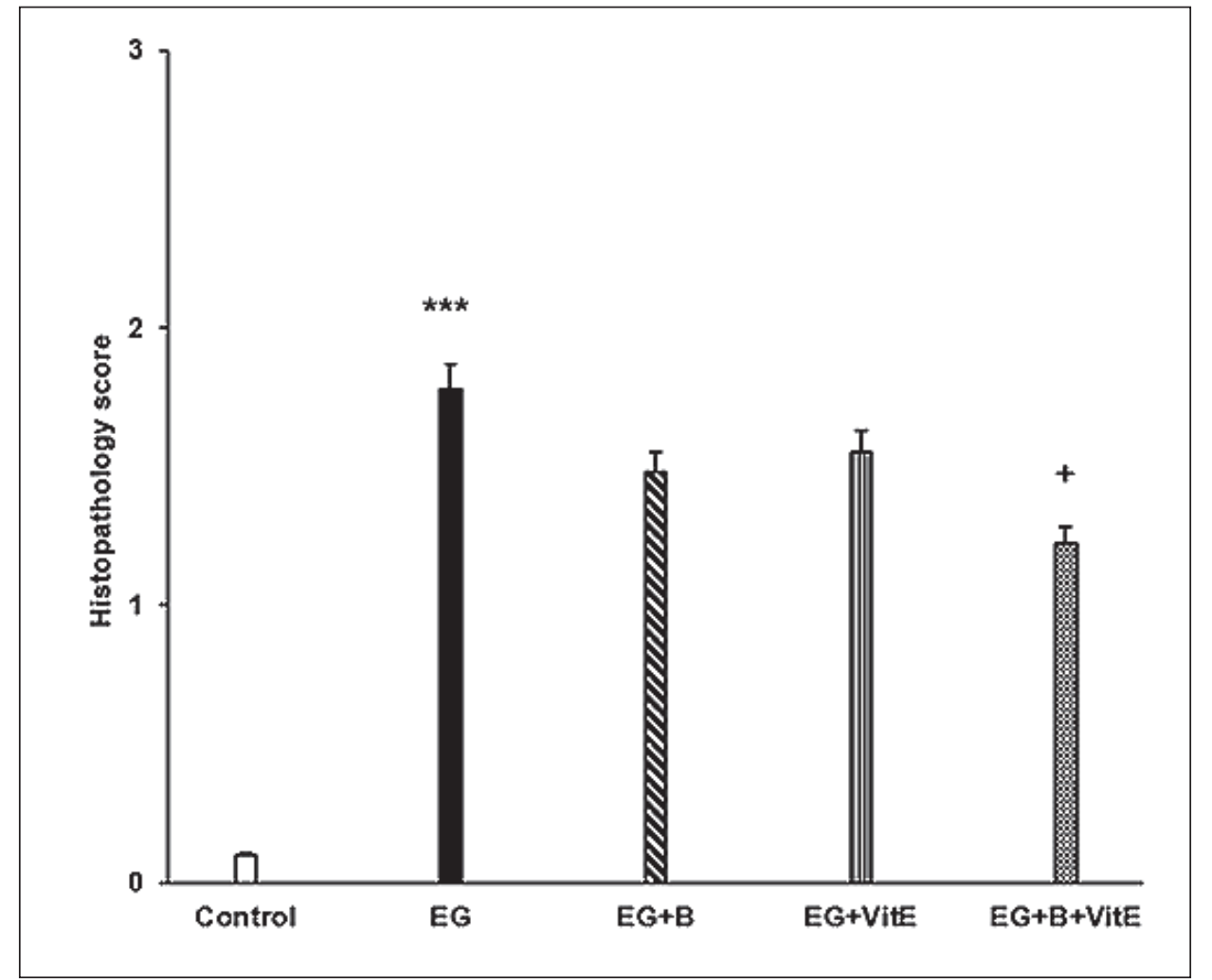


of the cell, attracting inflammatory cells, and thereby inflammatory response in renal tissue (Leussink et al. 2002). The destruction of the epithelium and dilation of the renal tubules observed in our study following administration of EG can be due to disruptions in the stability and function of mitochondria, increase in the LDH activity, infiltration of monocytes and macrophages into renal interstitial tissue, activation of Caspase 3 and increase of oxidative stress, as reported in other studies.

Chronic administration of EG solute in drinking water causes hyperoxaluria, which is the leading cause of kidney stones in animal studies (Huang et al. 2006). Our results showed that EG causes the formation of stones in all parts of kidney (cortex, medulla, and para cortex [juxtamedulla]). These results are consistent with other recent studies (Naghii et al. 2015; Kandhare et al. 2015; Shukla et al. 2014; Cho et al. 2014). The main mechanism of stone formation following administration of EG is related to EG metabolism pathway. Ethylene glycol is metabolized by alcohol dehydrogenase to glycol aldehyde followed by reaction with the aldehyde dehydrogenase produces glycolate. This is the main metabolite of ethylene glycol poisoning that induces metabolic acidosis. Oxalate is the main products of glycolate metabolism. It immediately binds to Calcium in tissues and urinary tract and forms kidney stones (Atakan et al. 2007). Results of Naghii et al. (2015) showed that two other mechanisms that contribute to the stone formation include elevated androgen levels in plasma following administration of EG as well as oxidative stress in the kidney that causes apoptosis in renal tubular epithelial cells and this process is one of the most important factors in kidney stone cascade event.

Histopathological examination results indicate that the destruction of tubules epithelial and their dilation in $\mathrm{EG}+\mathrm{Vit} \mathrm{E}$ group insignificantly decreased compared to EG group. There are several reports regarding to the role of free radicals and oxidative stress in the pathogenesis of kidney function. Free radicals cause cell death by damaging lipids, proteins and DNA molecules. (Huie and Padmaja 1993). Vitamin E, as an antioxidant, impairs epithelial cell death, and prevents the dilation of the renal tubular caused by oxidative stress (Badgujar et al. 2015). In the process of oxidative stress, Vit E inhibits fatty acid peroxidation in kidney tissue, maintains tight junctions between epithelial cells in the kidney tubules, and up regulates expression of tight junctions builder proteins such as Occludin (Arreola-Mendoza et al. 2009), reduces the ratio of pro-apoptotic ( $\mathrm{Bax}$ ) to anti-apoptotic $[\mathrm{Bcl}-2 / \mathrm{Bcl}-\mathrm{x}(\mathrm{L})]$ proteins (Post et al. 2002), increases anti-apoptotic protein expression of Bcl2 (Marsh et al. 2005), suppresses caspase-3 activity and also prevents the release of cytochrome $\mathrm{C}$ and Same/Diablo from mitochondria into the cytosol (Wu et al. 2005) and thereby protects kidney tubule epithelium structure against apoptosis and finally prevents dilation caused by oxidative stress. According to the results of the above studies, renal tubules protection observed in our study can be attributed to the protection against oxidative stress, maintaining the position and integrity of tight junctions as well as anti-apoptotic effect of Vit E.

The results also show that the deposits in three regions of the cortex, medulla and para cortex [juxtamedulla] in the EG+Vit E group is significantly decreased compared to the EG group. In this study, although the antioxidant status was not investigated but it was likely that formation of kidney stones in animals receiving ethylene glycol is due to induction of oxidative stress and ethylene glycol metabolism in the kidney tissue. According to this assumption, attenuation of the causes of oxidative stress in kidney tissues can effectively prevent stone formation. Therefore, the results obtained in the group EG+Vit E may be due to the antioxidant effects of this substance. It is reported that Antioxidants prevent the formation of kidney stones by reducing plasma androgen markers (Naghii et al. 2015). Antioxidant supplement can protect kidney tubules cell membrane, thus leading to prevent stone formation (Thamilselvan et al. 1997). Flavonoids compounds with lowering urinary citrate and increasing oxalate contribute to the prevention of calcium oxalate stones formation, and it is partly relevant to anti-inflammatory and antioxidant effects of flavonoids (Ahmed et al. 2013). Daily intake of 400 IU VitE for 60 days increased urinary citrate with increasing plasma levels of alpha-tocopherol, which is a key factor in the prevention of kidney stones (Theka et al. 2012). Interaction between the renal tubular epithelial cells and crystals in the urine (Khan 2011) and renal tubular epithelial integrity by secreting various factors such as Osteopontin (OPN) and citrate play a key role in the formation of kidney stones (De Yoreo et al. 2006). It is evident that the factors, which affect the kidney tubules epithelium, are involved in the mechanism of stone formation. Vit E can prevent the formation of stones by protecting the renal tubular epithelium and maintaining the integrity of the epithelium, which is a justification for the results of our study on the formation of the stones.

Boron appears to have a role in the prevention of injury and dilatation of the renal tubular epithelium. 
Histopathological examination results showed that the destruction of epithelial tubules and the ratio of dilatation in the $\mathrm{EG}+\mathrm{B}$ group compared to the $\mathrm{EG}$ group is decreased. The results of Moriyama and colleagues (2000) clearly show the role of oxidative stress in renal interstitial tissue damage. In our study, EG is the cause of oxidative stress. Boron is an antioxidant booster and like Vit $\mathrm{E}$ has antioxidant and antiinflammatory properties (Naghii 2014; Nielsen 2000; Armstrong and Spears 2003). So, it is expected that histopathologic findings in the $\mathrm{EG}+\mathrm{B}$ group would be similar to the EG+Vit E group. Thereby, reducing the destruction and the dilation of tubules epithelial of the $\mathrm{EG}+\mathrm{B}$ group in our study may be due to the antioxidant properties of boron in combat against oxidative stress.

The results of our study showed that the stones in three regions of the cortex, medulla, and para cortex [juxtamedulla] in the $\mathrm{EG}+\mathrm{B}$ group compared to the EG group significantly reduced. Renal tubular epithelial cells and urine crystals interaction (Khan 2011), as well as the integrity and safety of renal tubular epithelium by secreting various factors such as Osteopontin (OPN) and citrate (De Yoreo et al. 2006) have a key role in the formation of kidney stones. Therefore, boron with respect to the antioxidant role can somehow protect renal tubular epithelium against damage due to oxidative stress caused by the consumption of EG, and through maintaining the health of epithelium, which plays an important role in inhibition of stone formation. The antioxidant role of boron can be justified for stone reduction in both boron groups in our study. Recent studies have confirmed that boron has ameliorative effects against lipid peroxidation and oxidative stress and induced histopathological changes in liver, kidney and brain tissues by enhancing antioxidant defense mechanism, too (Ince et al. 2014; Coban et al. 2015) and it is clearly demonstrated that $\mathrm{Na} 2 \mathrm{~B} 4 \mathrm{O} 7.10 \mathrm{H} 2 \mathrm{O}$ as a source of boron is non-genotoxic and it has a remarkable antioxidant potential in vitro (Celikezen et al. 2015).

Our results showed that the final score of kidney stone formation, area of renal tubules, and renal tubular epithelial histological score in the $\mathrm{EG}+\mathrm{B}+\mathrm{Vit}$ E group reduced more efficiently compared to $\mathrm{EG}+\mathrm{B}$ and EG+Vit E groups, even though this decrease was not significant. According to the descriptions given in relation to the mechanisms of Vit $\mathrm{E}$ and boron separately, the results of our study in the combined group may be attributed to the cumulative effect of antioxidant properties of both boron and Vit E.

In conclusion, the results indicate that efficient effect of boron and Vit E supplements used separately and in combination has a synergistic effect in protection against oxidative stress and the formation of kidney stones.

\section{References}

Ahmed A, Wadud A, Jahan N, Bilal A, Hajera S. Efficacy of Adiantum capillus veneris Linn in chemically induced urolithiasis in rats. J Ethnopharmacol 146, 411-416, 2013.

Armstrong TA, Spears JW. Effect of boron supplementation of pig diets on the production of tumor necrosis factoralpha and interferon-gamma. J Anim Sci 81, 2552-2561, 2003.

Arreola-Mendoza L, Del Razo LM, Mendoza-Garrido ME, Martin D, Namorado MC, Calderon-Salinas JV, Reyes JL. The protective effect of alpha-tocopherol against dichromate-induced renal tight junction damage is mediated via ERK1/2. Toxicol lett 191, 279-288, 2009.

Atakan IH, Kaplan M, Seren G, Aktoz T, Gul H, Inci O. Serum, urinary and stone zinc, iron, magnesium and copper levels in idiopathic calcium oxalate stone patients. Int Urol Nephrol 39, 351-356, 2007.

Badgujar PC, Pawar NN, Chandratre GA, Telang AG, Sharma AK .Fipronil induced oxidative stress in kidney and brain of mice: Protective effect of vitamin E and vitamin C. Pestic Biochem physiol 118, 10-18, 2015.

Brigelius-Flohe R, Traber MG. Vitamin E: function and metabolism. FASEB Journal 13, 1145-1155, 1999.

Celikezen FC, Turkez H, Aydin E. The antioxidant and genotoxic activities of Na2B4O7. 10H2O In Vitro. Fresenius Environ Bull 24, 947-953, 2015.

Coban FK, Ince S, Kucukkurt I, Demirel HH, Hazman O. Boron attenuates malathion-induced oxidative stress and acetylcholinesterase inhibition in rats. Drug Chem Toxicol 38, 391-399, 2015.

De Yoreo JJ, Qiu SR, Hoyer JR. Molecular modulation of calcium oxalate crystallization. Am J Physiol Renal Physiol 291, F1123-1131, 2006.

Hess R, Bartels MJ, Pottenger LH. Ethylene glycol: an estimate of tolerable levels of exposure based on a review of animal and human data. Arch Toxicol 78, 671-680, 2004. 
Huang HS, Chen J, Chen CF, Ma MC. Vitamin E attenuates crystal formation in rat kidneys: roles of renal tubular cell death and crystallization inhibitors. Kidney Int 70, 699-710, 2006.

Huie RE, Padmaja S. The reaction of no with superoxide. Free Radic Res Commun 18, 195-199, 1993.

Hunt CD. The biochemical effects of physiologic amounts of dietary boron in animal nutrition models. Environ Health Perspect 102 Suppl 7, 35-43, 1994.

Cho HJ, Bae WJ, Kim SJ, Hong SH, Lee JY, Hwang TK, Choi YJ, Hwang SY, Kim SW. The inhibitory effect of an ethanol extract of the spores of Lygodium japonicum on ethylene glycol-induced kidney calculi in rats. Urolithiasis 42, 309-315, 2014.

Ince S, Kucukkurt I, Demirel HH, Acaroz DA, Akbel E, Cigerci IH. Protective effects of boron on cyclophosphamide induced lipid peroxidation and genotoxicity in rats. Chemosphere 108, 197-204, 2014.

IUPAC-IUB Joint Commission on Biochemical Nomenclature (JCBN). Nomenclature of tocopherols and related compounds. Recommendations 1981. Eur J Biochem 123, 473-475, 1982.

Kandhare AD, Patil MV, Bodhankar SL. L-Arginine attenuates the ethylene glycol induced urolithiasis in ininephrectomized hypertensive rats: role of KIM-1, NGAL, and NOs. Ren Fail 37, 709-721, 2015.

Kato YS, Kakizaki H. Yachiku S. Influence Of estrus status on urinary chemical rameters related to urolithiasis. Urol Res 33, 476-480, 2005.

Khan SR. Role of renal epithelial cells in the initiation of calcium oxalate stones. Nephron Exp Nephrol 98, e5-6, 2004.

Khan SR. Crystal/cell interaction and nephrolithiasis. Arch Ital Urol Androl 83, 1-5, 2011.

Khan SR. Is oxidative stress, a link between nephrolithiasis and obesity, hypertension, diabetes, chronic kidney disease, metabolic syndrome? Urol Res 40, 95-11, 2012.

Leussink BT, Nagelkerke JF, van de Water B, Slikkerveer A, van der Voet GB, Srinivasan A, Bruijn JA, de Wolff FA, de Heer E. Pathways of proximal tubular cell death in bismuth nephrotoxicity. Toxicol Appl Pharmacol 180, $100-109,2002$.

Marsh SA, Laursen PB, Pat BK, Gobe GC, Coombes JS. Bcl-2 in endothelial cells is increased by vitamin E and alphalipoic acid supplementation but not exercise training. J Mol Cell cardiol 38, 445-451, 2005.

Moriyama T, Kawada N, Nagatoya K, Horio M, Imai E, Hori M. Oxidative stress in tubulointerstitial injury: therapeutic potential of antioxidants towards interstitial fibrosis. Nephrol Dial Transplant 15 Suppl 6, 47-49, 2000.

Naghii MR. Boron and antioxidants complex: a new concept for the treatment of kidney stones without rigorous pain. Endocr Regul 48, 120-125, 2014.

Naghii MR, Mofid M, Hedayati M, Khalagi K. Antioxidants inhibition of high plasma androgenic markers in the pathogenesis of ethylene glycol (EG)-induced nephrolithiasis in Wistar rats. Urolithiasis 42, 97-103, $2014 \mathrm{a}$.

Naghii MR, Eskandari E, Mofid M, Jafari M, Asadi MH. Antioxidant therapy prevents ethylene glycol-induced renal calcium oxalate crystal deposition in Wistar rats. Int Urol Nephrol 46, 1231-1238, $2014 \mathrm{~b}$.

Naghii M, Jafari M, Mofid M, Eskandari E, Hedayati M, Khalagie K. The efficacy of antioxidant therapy against oxidative stress and androgen rise in ethylene glycol induced nephrolithiasis in Wistar rats. Hum Exp Toxicol 34, 744-754, 2015.

National Kidney and Urologic Diseases Information Clearing-house. Kidney Stones in Adults. NIH Publication no. 08-2495, 2007.

Nielsen FH. The emergence of boron as nutritionally important throughout the life cycle. Nutrition 16, 512-514, 2000.

Patocka J, Hon Z. Ethylene glycol, hazardous substance in the household. Acta Medica (Hradec Kralove) 53, $19-23,2010$.

Poldelski V, Johnson A, Wright S, Rosa VD, Zager RA. Ethylene glycol-mediated tubular injury: identification of critical metabolites and injury pathways. Am J kidney Dis 38, 339-348, 2001.

Pomara C, Fiore C, D’Errico S, Riezzo I, Fineschi V. Calcium oxalate crystals in acute ethylene glycol poisoning: a confocal laser scanning microscope study in a fatal case. Clin Toxicol 46, 322-324, 2008.

Portilla D. Apoptosis, fibrosis and senescence. Nephron Clin Pract 127, 65-69, 2014.

Post A, Rucker M, Ohl F, Uhr M, Holsboer F, Almeida OF, Michaelidis TM. Mechanisms underlying the protective potential of alpha-tocopherol (vitamin E) against haloperidol-associated neurotoxicity. Neuropsychopharmacology 26, 397-407, 2002.

Scales CD Jr., Smith AC, Hanley JM, Saigal CS. Prevalence of kidney stones in the United States. Eur urol 62, 160-165, 2012.

Shukla AB, Mandavia DR, Barvaliya MJ, Baxi SN, Tripathi CR. Evaluation of anti-urolithiatic effect of aqueous extract of Bryophyllum pinnatum (Lam.) leaves using ethylene glycol-induced renal calculi. Avicenna J phytomed 4, 151-159, 2014. 
Small DM, Morais C, Coombes JS, Bennett NC, Johnson DW, Gobe GC. Oxidative stress-induced alterations in PPAR-gamma and associated mitochondrial destabilization contribute to kidney cell apoptosis. Am J Physiol Renal Physiol 307, F814-822, 2014.

Thamilselvan S, Hackett RL, Khan SR. Lipid peroxidation in ethylene glycol induced hyperoxaluria and calcium oxalate nephrolithiasis. J urol 157, 1059-1063, 1997.

Theka T, Rodgers A, Lewandowski S, Webber D, Allie-Hamdulay S. Effects of vitamin E ingestion on plasma and urinary risk factors for calcium oxalate urolithiasis in two population groups having different stone-risk profiles: evidence of different physiological handling mechanisms. Urol Res 40, 113-120, 2012.

Watanabe M, Hitomi M, van der Wee K, Rothenberg F, Fisher SA, Zucker R, Svoboda KK, Goldsmith EC, Heiskanen KM, Nieminen AL. The pros and cons of apoptosis assays for use in the study of cells, tissues, and organs. Microsc Microanal 8, 375-391, 2002.

Wu SJ, Ng LT, Lin CC. Effects of antioxidants and caspase-3 inhibitor on the phenylethyl isothiocyanate-induced apoptotic signaling pathways in human PLC/PRF/5 cells. Eur J pharmacol 518, 96-106, 2005. 